\title{
A Model For EVIDENCE-BASED ElECTROTHERAPY IN AN UNDERGRADUATE CURRICULUM
}

\begin{abstract}
All physiotherapists have a responsibility not only to their patients but also to their colleagues and health care funding sources to provide interventions that are sound in theory and supported by well-controlled experimental studies. The principles of evidence-based practice should be implemented in an undergraduate curriculum in order to assist students to acquire skills to obtain and use relevant information. The aim of this paper is to present a model to integrate the activities of patient assessment and information processing, critical appraisal and evidence-based practice into clinical decisionmaking of electrotherapy application. The model as well as the results and evaluation thereof are discussed.
\end{abstract}

KEYWORDS: EVIDENCE-BASED PRACTICE, PHYSICAL THERAPY, ELECTROTHERAPY, AND EDUCATION.

\section{INTRODUCTION}

Physiotherapists, regardless of the country and context in which they work, are facing increasing pressure to provide treatment, which is evidence-based. Evidence-based practice is defined as "using the best available scientific evidence to guide practice" (EvidenceBased Medicine Working Group, 1992). There is an increasing need for an evidence-based approach to patient care as the cost and choice of treatment must be justified.

Research and clinical practice must be integrated to ensure the growth of evidence-based practice in physiotherapy. Treatment approaches clearly demonstrated to be ineffective for a particular condition, must be discarded and clinical practice guidelines, where available, must be implemented. Questions arising from the implementation of new or altered treatment approaches should form the basis of future studies, thus consolidating the link between clinical practice and research. Linking research and clinical practice is mandatory if we are to remain a credible health care profession and in all probability is essential for the survival of the physiotherapy profession (Culham, 1998).

Patients have the right to receive treatment, which has a theoretical base and has been demonstrated to be effective for the management of their condition. Each physiotherapist thus has a responsibility to patients, colleagues and to health care funding sources to provide interventions that are sound in theory and supported by well-controlled experimental studies.

The primary goal of physiotherapy is to provide the highest quality of care in order to achieve the best outcome for patients in a cost-effective manner. The care process involves assessment, physical diagnosis, identification of clientcentred goals (outcomes), selection of effective therapeutic interventions and evaluation of progress. To make sound decisions throughout this process, physiotherapists require valid information (Thomson - O'Brien \& Moreland, 1998).

How do we as professionals, move towards a more evidence-based approach to patient care? Three steps must be taken to achieve this outcome. The first involves knowledge generation (research); evidence must be available before practice can be evidence-based. The second involves knowledge transmission (education); the information must be readily available to physiotherapists. The third step, knowledge application; involves the incorporation of new knowledge into clinical practice and evaluation of outcomes in the clinical setting (Culham, 1998).

Perhaps the most promising method of implementing evidence-básed practice is to assist undergraduate students to acquire skills to obtain and use relevant information. Those responsible for undergraduate curriculum development and teaching thus have a key role in facilitating the process of implementing valid research findings in clinical practice (Thomson - O'Brien \& Moreland, 1998).

At the Physiotherapy Department, University of Pretoria, the importance of following an evidence-based approach during undergraduate training has been recognised. As students complete their basic electrotherapy training at the end of their second year of study, a decision was made to follow an evidence-based approach with the implementation of electrotherapy in clinical practice during the third year of study. The new model of electrotherapy application in the third year curriculum was introduced in March 1999.

\section{AlM}

The main aim of this paper is to present a model of integrated activities of patient assessment and information processing, critical appraisal and evidence-based

CORRESPONDENCE:

M Papadopoulos

Department of Physiotherapy University of Pretoria

PO Box 667, Pretoria 0001

Tel: (0.12) 354-2023

Fax: (012) 354-1226

E-mail: mpapadop@postillion.up.ac.za 
practice in clinical decision-making of electrotherapy application. A secondary aim is to evaluate the model and to present the results.

\section{DEFINITION OF TERMS}

Evidence: Anything that establishes a fact or gives reason for believing something (Oxford paperback dictionary, 1979). The strength of the evidence is related to the methods of obtaining it. Some methods are more subject to bias than others eg, the evidence derived from a case series study is weaker than that derived from a randomised controlled trial (Cook DJ et al, 1992).

Evidence-based practice: The process of using the results of sound research (as determined by critical appraisal) to guide clinical care within the context of the individual client and local environment. (Thomson- O'Brien \& Moreland, 1998).

Critical Appraisal: The evaluation of research papers to determine the validity and applicability of the conclusions. As a result of the critical appraisal process, a reader is able to judge how much confidence to place in the conclusions of the study and whether the results apply to their patient/clients (Thomson - O'Brien \& Moreland, 1998).

\section{METHOD AND MODEL}

Students had to complete 3 assignments based on the model that consists of 5 stages, throughout the year. Students are tested in a clinical setting to determine if they have mastered the required learning in electrotherapy. The theory component is evaluated by means of a written assignment that the students hand in 2 weeks after the practical assessment. This consists of 2 parts namely the critical appraisal of an article (stage III) and the educational prescription (stage I, II, IV and V). The different stages of the model will be described briefly.

\section{Stage I}

During the first stage the student is required to assess and treat a patient.
At any point during this stage students may identify the need for further information about the patient's condition. This would assist them to provide the best possible care. A number of questions may arise concerning the management of the patient, eg the effectiveness of different treatment modalities may not be known to the student. The student is required to formulate a question consisting of the following components: clinical task, patient or problem, intervention and outcome (see figure I). Clinical task refers to the type of question that is posed and may be regarding a clinical finding, differential diagnosis, prognosis, therapy etc (Sackett et al, 1997). Thus, the need for certain information is specified during stage one.

\section{Stage II}

During the second stage, information regarding the patient's condition and most effective treatment modality must be obtained and processed. Traditionally, information has been located in textbooks or journals in libraries.

\section{FIGURE 1: An integrated model for evidence-based electrotherapy}

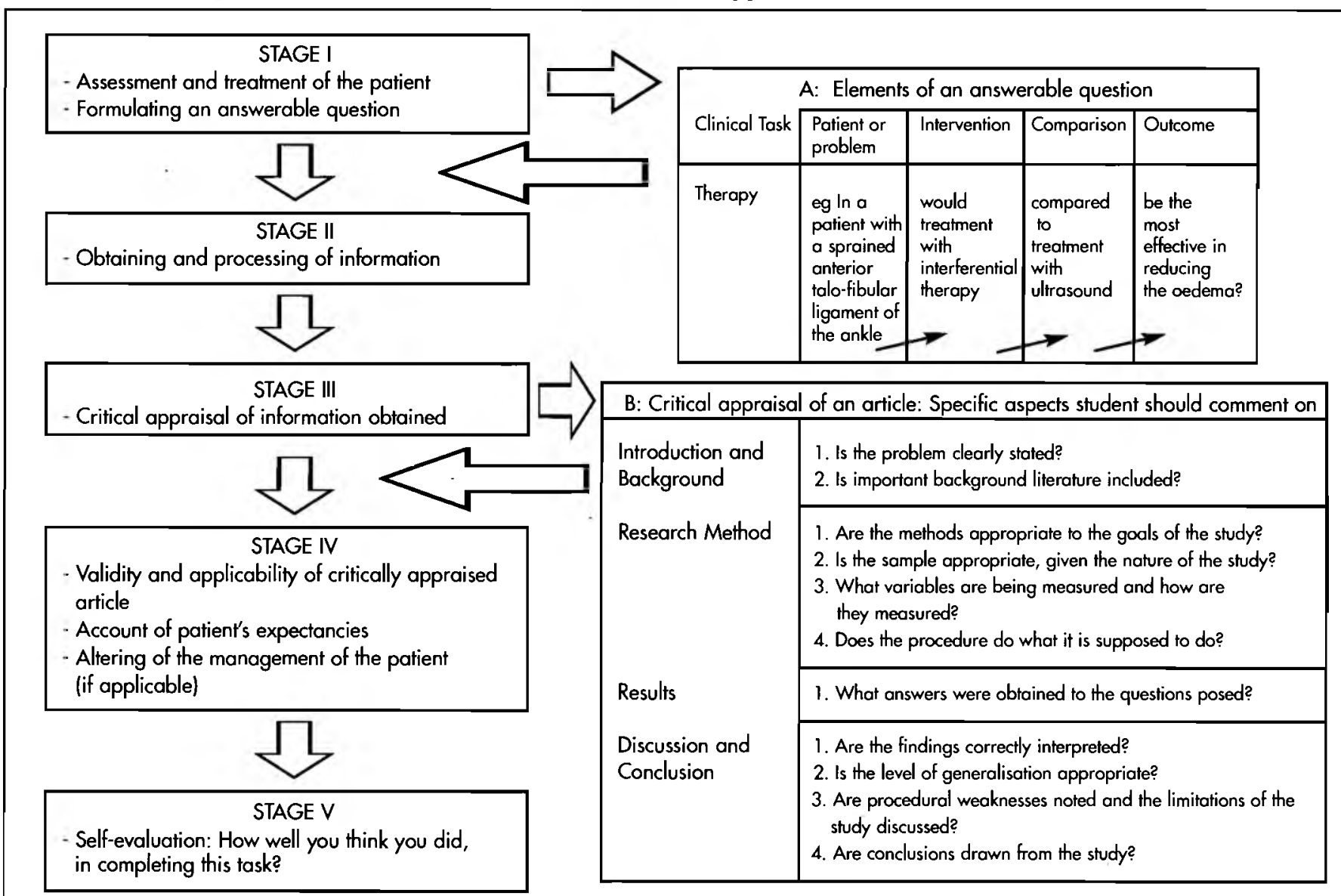


Other recent options that should be used to obtain relevant citations include MEDLINE and CINAHL databases. The student has to report on the type of search that was performed, the keywords used during the search, as well as the type of information found as a result of the search.

\section{STAGE III}

Stage three consists of the critical appraisal of one of the articles the student found during his/her literature search. The student should motivate why this article seems to be appropriate in providing the information he/she requires to answer the question posed in stage 1 . With the critical appraisal the students are expected to comment on certain specific aspects of the article (see figure 1).

\section{STAGE IV}

During stage four, the student has to decide whether the information obtained from the critically appraised article is applicable to his/her patient. Students have to comment on the validity and applicability of the critically appraised article, and give an opinion on how this new knowledge will alter the management of or approach to the patient.

It is essential however that the student should acknowledge at this stage the personal beliefs of the patient, the community and cultural environment that may influence the type of treatment that the patient may find acceptable. The student should realise that' this factor could influence the implementation of this evidence-based approach.

\section{STAGE $V$}

Stage five is a self-evaluative stage where students are expected to comment on how well they think they did in completing the task. An aspect that should be considered during this stage is whether the student is still having difficulty in formulating an answerable question.

The self-evaluation should include aspects regarding the students own performance in searching for the best external evidence. Self-evaluation should also assess the student's performance in critically appraising external evidence for its validity and potential usefulness as well as the accuracy and efficiency in adjusting some of the critical appraisal measures to fit the individual patient.

\section{EVALUATION OF THE MODEL}

The model was evaluated during October 1999 by means of a qualitative method. Students were asked to comment on their experience of this model.

\section{RESULTS}

A total of 125 comments were received from 39 students. Comments were classified either as positive or negative experiences or responses. Seventy positive responses (see figure 2) and 55 negative responses (see figure 3 ) were identified. Further results will consequently be discussed.

\section{DISCUSSION}

The incorporation of evidence from clinical research into clinical practice

\section{FIGURE 2: Positive comments on the integrated electrotherapy model (70 positive responses).}

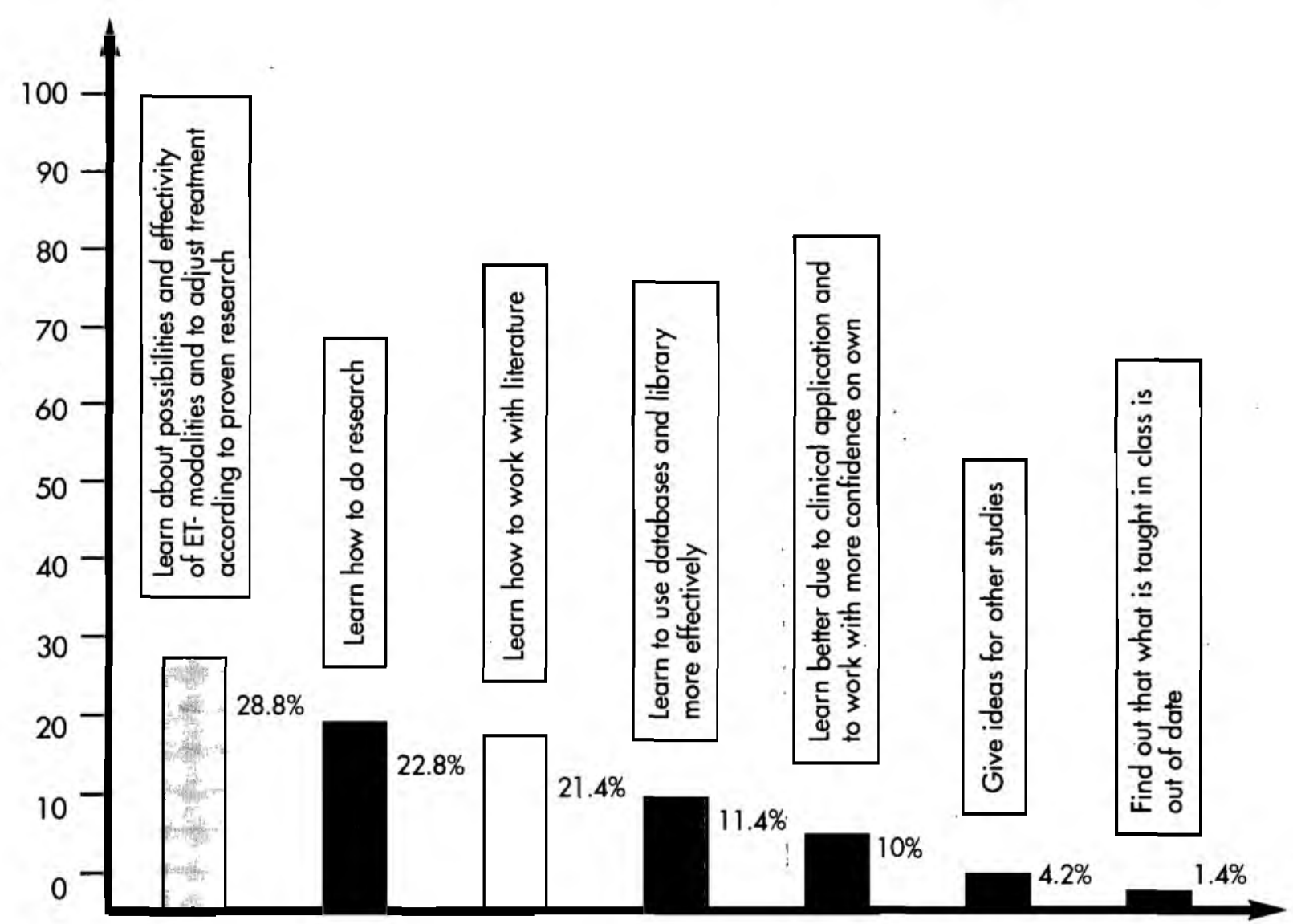


requires that the student masters and maintains a continually expanding set of skills. In much the same way that time and effort is required to be able to accurately detect, characterise and assess a clinical problem, evidence- based practice requires that students learn how to formualte a question and learn to obtain a published article or information relevant to such a question. In addition the student learns to assess validity of relevant information, learns to identify the clinically useful results and place these results into a format that can be applied to patient care.

The success of learning by inquiry depends heavily on being able to find the current best evidence to manage clinical problems. Such a task can be achieved quickly and be highly rewarding, or be time consuming and frustrating. During this process the student will learn where to search for the best evidence and to design a search strategy. Skills in the utilisation of electronic media and other databases are needed or need to be developed. Considering the positive responses from students, $11,4 \%$ indicated that they learnt how to use databases and the library more effectively (see figure 2).

During the process of critical appraisal of the relevant literature (stage III), the students are exposed to research terminology, and methodology. The highest number of the positive responses (see figure 2) indicated that this model helps students to "learn how to do research" $(22,8 \%)$ and "to learn how to work with literature" $(21,4 \%)$. This awareness could have a positive effect on the student's future research career as potential research topics and the need for research could be highlighted and exposed as is evident in $4,2 \%$ of the positive responses (see figure 2 ). In the field of physiotherapy, the student is also confronted with the lack of literature $(31,15 \%$ of negative responses) and the low methodological quality of existing research.

Of the negative responses, $45,45 \%$ indicated that students experience this model to be very time consuming. The process of finding literature (gaining experience with using electronic databases) and critically appraising an article is a timeous process. Responses of "stressful" (1,8\%) and "library not always very helpful" $(1,8 \%)$ can probably be linked to the inexperience of students in finding literature or to the time limit of 2 weeks in which students have to complete the assignment. However, it is the view of the authors, that as the student becomes more experienced in finding the relevant literature, and becomes more knowledgeable and gains more confidence in critically appraising the literature, the less time consuming the process will be.

Although both physiotherapy educators and clinicians really do need to keep up to date with clinically important information, it is a general fact that they fail to do so for many different reasons eg, the lack of time to read clinical journals $(1,4 \%$ of positive student responses (figure 2) mentioned that they realised that what they were taught in class is out of date). The result of this is that unfortunately, it leads to progressive declines

FIGURE 3: Negative comments on the integrated electrotherapy model (55 negative responses).

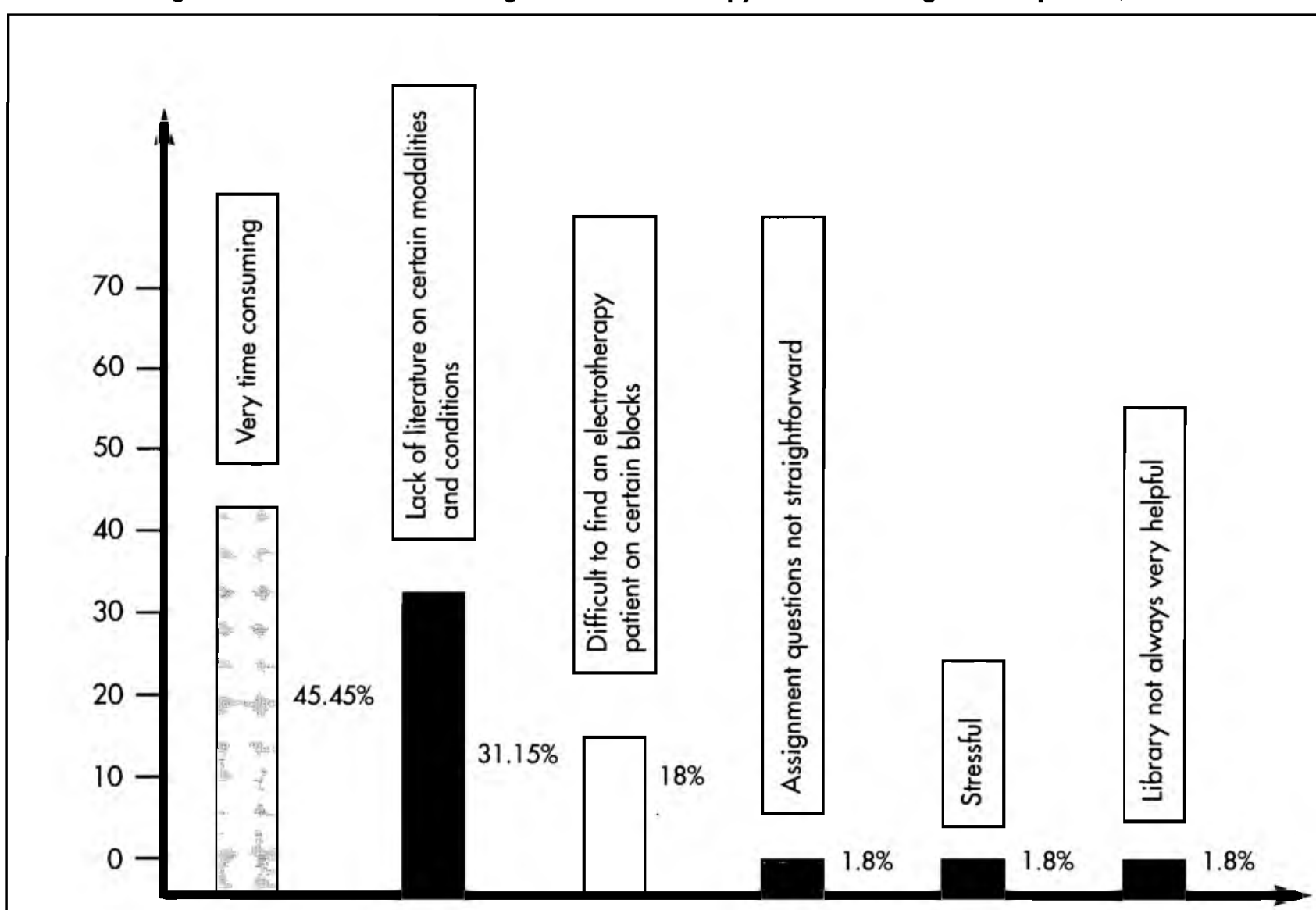


in clinical competencies of physiotherapists after completion of the formal training (Ramsey, et al 1991; Evans et al, 1986). The student on the other hand needs constant individualised feedback about what he is doing correctly or incorrectly. Very often the student may be in the difficult position of receiving conflicting advice and opinions from different educators and clinicians. The positive responses( $28,8 \%$ ), indicated that this model enables students to learn more about the possibilities and effectiveness of electrotherapy modalities (see figure 2). Ten percent (10\%) of the responses further indicated that students learn better when clinically applying electrotherapy and the model enabled them to work with confidence on their own (see figure 2).

Due to logistic reasons it was occasionally expected from students to do an electrotherapy assignment during a clinical block (18\% of negative responses) where it was difficult to find an appropriate problem to be managed with electrotherapy. This resulted in inappropriate clinical question formulation and problem management. In order to overcome this, the department decided to utilise this model in other clinical settings, eg pulmonary physiotherapy, not just in the field of electrotherapy.

It is thus evident that this model enables the student to become more efficient in articulating what he/she needs to know and how to learn it.
The experience of this model amongst educators and clinicians with respect to student knowledge, technique application and confidence still needs to be assessed.

As Harris (1996) stated: "We can choose to remain non-reflective practitioners, learning about and practising new treatment techniques because they are new and different and exciting, or we can move forward as professionals - with sound theoretical and scientific support underlying our treatment practices".

\section{CONCLUSION}

Both physiotherapy educators and clinicians face a great challenge in trying to integrate sound research findings into clinical practice. Difficulties experienced include the amount of new information, as well as a lack of skills in accessing and appraising relevant studies. This model provides a framework for linking clinical decision making and relevant research at an undergraduate level, thereby preparing students to become life-long, self-directed learners.

\section{REFERENCES}

Cook DJ, Guyatt GH, Laupacis A, Sackett DL 1992 Rules of evidence and clinical recommendations on the use of antithrombotic agents. Chest 102:305S-311S
Culham E 1998 Evidence-based practice and professional credibility. Physiotherapy Theory and practice, June 14(2):65-67

Evans CE, Haynes RB. Birkett NJ, Gilbert JR, Taylor DW, Sackett DL, Johnston ME, Hewson SA 1986 Does a mailed continuing education program improves clinician performance? Results of a randomised trial in antihypertensive care JAMA 255:501-4

Evidence-Based Medicine Working Group 1992 Evidence-based medicine: A new approach to teaching the practice of medicine. Journal of the American Medical Association 268:2420-2425

Harris SR 1996 How should treatments be critiqued for scientific merit? Physical Therapy 76(2):175-181

Ramsey PG, Carline JD, Inuit TS, Larson EB, LoGerfo JP, Norcini JJ, Wenrich MD 1991 Changes over time in the knowledge base of practising internists. JAMA 266:1103-7

Sackett DL, Richardson WS, Rosenberg W, Haynes RB 1997 Evidence-Based Medicine. How to practice and teach EBM, Churchill Livingstone

The Oxford paperback dictionary, Oxford University press, Oxford 1979

Thomson -'O'Brien MA, Moreland J 1998 Evidence-Based practice information circle. Physiotherapy Canada Summer: 184-189 